\title{
Long-Term Follow-Up of Advanced Liver Disease after Sustained Virological Response to Treatment of Hepatitis C with Direct-Acting Antivirals: Outcomes from a Real-World Portuguese Cohort
}

\author{
Tiago Pereira Guedes ${ }^{a}$ Pedro Fragoso $^{b}$ Carolina Lemos ${ }^{c, d}$ \\ Mónica Garrido ${ }^{a}$ Joana Silva ${ }^{a}$ Daniela Falcão ${ }^{a}$ Luís Maia $^{a}$ Teresa Moreira ${ }^{a}$ \\ José Manuel Ferreira ${ }^{a}$ Isabel Pedroto ${ }^{a}$ \\ ${ }^{a}$ Department of Gastroenterology, Centro Hospitalar Universitário do Porto, Porto, Portugal; 'b Instituto de Ciências \\ Biomédicas Abel Salazar, Universidade do Porto, Porto, Portugal; ' UnIGENe, Instituto de Biologia Molecular e Celular \\ (IBMC) and Instituto de Investigação e Inovação em Saúde (i3S), Universidade do Porto, Porto, Portugal; ${ }^{\mathrm{d} D e p a r t m e n t ~ o f ~}$ \\ Population Studies, Instituto de Ciências Biomédicas Abel Salazar, Universidade do Porto, Porto, Portugal
}

\section{Keywords}

Antiviral agents $\cdot$ Hepatocellular carcinoma $\cdot$ Hepatitis C . Liver cirrhosis · Sustained virological response

\section{Abstract}

Background: Direct-acting antivirals (DAA) have revolutionized hepatitis $C$ treatment, with high sustained virological response (SVR) rates reported, even in historically difficultto-treat groups. SVR is associated with a decreased risk of hepatocellular carcinoma (HCC), need for transplantation, and overall and liver-related mortality. Data from real-life cohorts on the medium- to long-term outcomes of patients with advanced liver disease and DAA-induced SVR are still missing. Objectives: To report and analyze the long-term outcomes of DAA-induced SVR in a real-life cohort of patients with advanced liver disease. Method: In this retrospective, longitudinal, single-center study, we collected data from patients with chronic hepatitis $C$ infection and advanced liver disease (cirrhosis or advanced fibrosis) that had initiated DAA treatment between February 2015 and January 2017. Results: A total of 237 patients were included. A treatment completion rate of $98.7 \%$ and an SVR rate of $97.8 \%$ (intention to treat: $96.6 \%)$ were found. Of the 229 patients with SVR, $67.2 \%$ were cirrhotic $(64.2 \%$ Child-Pugh class A; $3.1 \%$ Child-Pugh class B) and $32.8 \%$ had stage F3 fibrosis, with an average follow-up of 28 months. The overall mortality rate was 19/1,000 person-years and the liver-related mortality rate was $9.5 / 1,000$ person-years. The hepatic decompensation incidence rate was $25 / 1,000$ person-years and the HCC incidence rate was $11.6 / 1,000$ person-years. There was a sustained increase in serum platelet values during up to 2 years of follow-up. A history of pretreatment decompensation and baseline platelet and albumin values were significantly associated with the occurrence of adverse liver events after the end of treatment. Conclusions: A DAA-induced SVR remains durable and is associated with an excellent clinical prognosis in patients with compensated advanced liver disease and with improvement or disease stabilization in decompensated patients. SVR is associated with a low risk of yet does not prevent - HCC occurrence or disease progression, especially in the presence of other causes of liver injury. It is recommended that these patients be kept under surveillance.

(c) 2019 Sociedade Portuguesa de Gastrenterologia Published by S. Karger AG, Basel

\section{KARGER}

karger@karger.com www.karger.com/pjg
(C) 2019 Sociedade Portuguesa de Gastrenterologia Published by S. Karger AG, Basel

Karcer

Open access

This article is licensed under the Creative Commons AttributionNonCommercial-NoDerivatives 4.0 International License (CC BYNC-ND) (http://www.karger.com/Services/OpenAccessLicense). Usage and distribution for commercial purposes as well as any distribution of modified material requires written permission.
Tiago Pereira Guedes

Department of Gastroenterology, Centro Hospitalar Universitário do Porto Largo do Prof. Abel Salazar

PT-4099-001 Porto (Portugal)

E-Mail tiagoapguedes@gmail.com 
Seguimento a longo prazo da doença hepática avançada após cura do vírus $\mathrm{C}$ com antivíricos de ação direta: dados de uma coorte Portuguesa

\section{Palavras Chave}

Agentes antivirais - Carcinoma hepatocelular - Cirrose hepática $\cdot$ Hepatite $C \cdot$ Resposta virológica sustentada

\section{Resumo}

Introdução: Os antivíricos de ação direta (AAD) revolucionaram o tratamento da hepatite $C$ ao atingirem elevadas taxas de resposta virológica sustentada (RVS), mesmo em grupos historicamente difíceis de tratar. A RVS associa-se a uma diminuição do risco de carcinoma hepatocelular (CHC), necessidade de transplantação e mortalidade, global e de causa hepática. São ainda insuficientes de coortes reais na literatura dados que permitam avaliar a extensão dos benefícios clínicos a médio-longo prazo do atingimento de uma RVS com os AAD. Objetivos: Reportar e analisar o impacto a longo prazo da RVS numa coorte real de doentes com doença hepática avançada, tratados com AAD. Métodos: Estudo unicêntrico, retrospetivo, longitudinal com inclusão de doentes com hepatite $C$ crónica com cirrose ou fibrose avançada, que iniciaram tratamento com AAD de fevereiro de 2015 a janeiro de 2017. Resultados: Foram incluídos 237 doentes. Verificou-se uma taxa de retenção no tratamento de 98.7\% com uma taxa de RVS de $97.8 \%$ (intention to treat: 96.6\%). Dos 229 doentes curados, $67.2 \%$ eram cirróticos (64.2\% Child-Pugh A, 3.1\% Child-Pugh B) e 32.8\% F3, com um seguimento médio de 28 meses. A taxa de mortalidade global foi de 19/1,000 pessoas-ano e de mortalidade associada à doença hepática de $9.5 / 1,000$ pessoasano. A incidência de eventos de descompensação hepática foi de 25/1,000 pessoas-ano e a de $\mathrm{CHC}$ foi de $11.6 / 1,000$ pessoas-ano. Verificou-se um aumento sustentado dos valores séricos de plaquetas até 2 anos de seguimento. A história de eventos de descompensação hepática, concentração de plaquetas e albumina prétratamento encontrou-se significativamente associada a eventos adversos hepáticos durante o seguimento. Conclusões: A cura virológica após tratamento com AAD é sustentada no tempo, encontrando-se associada a um excelente prognóstico clínico em doentes com doença hepática avançada compensada, e a uma melhoria ou estabilização da doença em doentes descompensados. O atingimento de RVS associa-se a um baixo risco de $\mathrm{CHC}$, não o eliminando, e de progressão da doença, sobretudo perante a presença de outros cofatores de agressão hepática, recomendando-se a manutenção do seguimento destes doentes. $\quad 2019$ Sociedade Portuguesa de Gastrenterologia Publicado por S. Karger AG, Basel

\section{Introduction}

It is estimated that 71 million people worldwide are infected with the hepatitis $\mathrm{C}$ virus (HCV), with an overall prevalence of $1 \%$ [1]. HCV is the major cause of hepatocellular carcinoma (HCC) and cirrhosis-related mortality in developed countries [2]. Approximately one-third of patients will present with advanced chronic liver disease, its prevalence having doubled in the last 10 years [2]. In Portugal, since the creation of the Hepatitis C Portal of the National Authority for Medicines and Health Products in 2017, more than 17,000 people have been reported as chronically infected [3].

Direct-acting antivirals (DAA) present high rates of sustained virological response (SVR), even in historically difficult-to-treat groups such as patients with advanced liver disease or treatment-experienced patients [4]. The SVR rates with DAA regimens exceed $95 \%$, with an excellent safety and tolerability profile, which has widened the spectrum of candidates for HCV treatment as well as HCV-cured patients [5, 6]. In Portugal, until June 2019, around 22,800 DAA treatments had been initiated, with an SVR rate of $96.4 \%$ [7].

The aims of antiviral therapy are to achieve virological cure; to prevent progression of liver disease and the occurrence of cirrhosis-related complications; to increase the quality of life and survival of patients; to remove the stigma associated with infection; and to prevent future transmission of the virus [8]. The accumulated data from interferon (IFN)-based treatments demonstrate a beneficent long-term clinical effect in patients who achieve SVR, by preventing the development of esophageal varices (EV), reducing the risk of HCC and the need for liver transplantation, and reducing liver-related mortality [2, 9-12]. The long-term histological regression of the grade of fibrosis was also documented, which reinforces the dynamic nature of fibrosis progression in the natural course of the disease $[4,13,14]$. Achieving SVR is also associated with resolution of extrahepatic hepatitis $\mathrm{C}$ manifestations and improvement in metabolic parameters, with a consequent reduction in cardiovascular events, contributing to a lower non-liver-related mortality rate [6].

Despite the description of DAA-induced SVR rates in a real-world Portuguese cohort [15], there are still insuf- 
ficient published data from real-world cohorts regarding the extent of medium- to long-term clinical benefits of SVR achieved with these treatments. This study aims to report and analyze the long-term impact of SVR in a realworld, single-center cohort of patients with advanced liver disease treated with DAA.

\section{Subjects and Methods}

\section{Patients}

We retrospectively reviewed 237 patients with advanced liver disease (fibrosis stage F3 or F4) that had initiated treatment with DAA between February 2015 and January 2017 at the Department of Gastroenterology of Centro Hospitalar Universitário do Porto, a tertiary and university-setting hospital.

The exclusion criteria comprised coinfection with another hepatitis virus or human immunodeficiency virus, a previous liver transplantation, and an HCC diagnosis at baseline. The stage of fibrosis was evaluated by FibroScan ${ }^{\circledR}$ (Echosens, Paris, France; F3: 9.6-12.4 kPa; F4: $\geq 12.5 \mathrm{kPa}$ ), a previous liver biopsy (METAVIR score), or based on the clinical diagnosis of cirrhosis. Patients with cirrhosis had had a hepatic ultrasound (US) and esophagogastroduodenoscopy at least 6 months prior to the beginning of the treatment. EV were characterized according to the Baveno classification (size: small $<5 \mathrm{~mm}$, large $>5 \mathrm{~mm}$ ) [16] and the position in eradication plan (primary, secondary, or eradicated). The choice of treatment regimen and duration were at the discretion of the attending physician based on the EASL recommendations applicable at the time. The data were obtained from the electronic clinical records.

\section{Follow-Up Parameters}

SVR at 12 weeks was defined as undetectable HCV RNA 12 weeks after the end of treatment (EOT). HCV RNA quantification was performed for every patient by quantitative real-time PCR (cobas ${ }^{\circledR} \mathrm{HCV}$ Test; Roche; linear range: $15 \mathrm{IU} / \mathrm{mL}$ to $1.0 \times 10^{8} \mathrm{IU} /$ $\mathrm{mL}$ ). The patients were assessed at EOT, 12 and 24 weeks after EOT, and thereafter twice or once a year, at the discretion of the attending physician. At each visit, the following parameters were evaluated: platelet count, transaminases, bilirubin, albumin, creatinine, glucose, INR, $\alpha$-fetoprotein, and the viral load. ChildPugh (CP) and MELD scores were calculated. Hepatic US was performed every 6 months, and further tests for clarification of US findings were performed as needed. Transient elastography after EOT was performed at the discretion of the attending physician.

Liver decompensation events were defined as: ascitic decompensation (de novo or worsening ascites), portal hypertensive bleeding, hepatic encephalopathy, and spontaneous bacterial peritonitis. Liver-related mortality was defined as death resulting from hepatic decompensation or HCC progression. Considering the occurrence of HCC, data were collected regarding staging, established treatment, diagnostic and treatment timing, and clinical outcomes.

\section{Statistical Analysis}

Descriptive statistics were applied for the different variables. Student's $t$ test for independent samples was used to compare con-

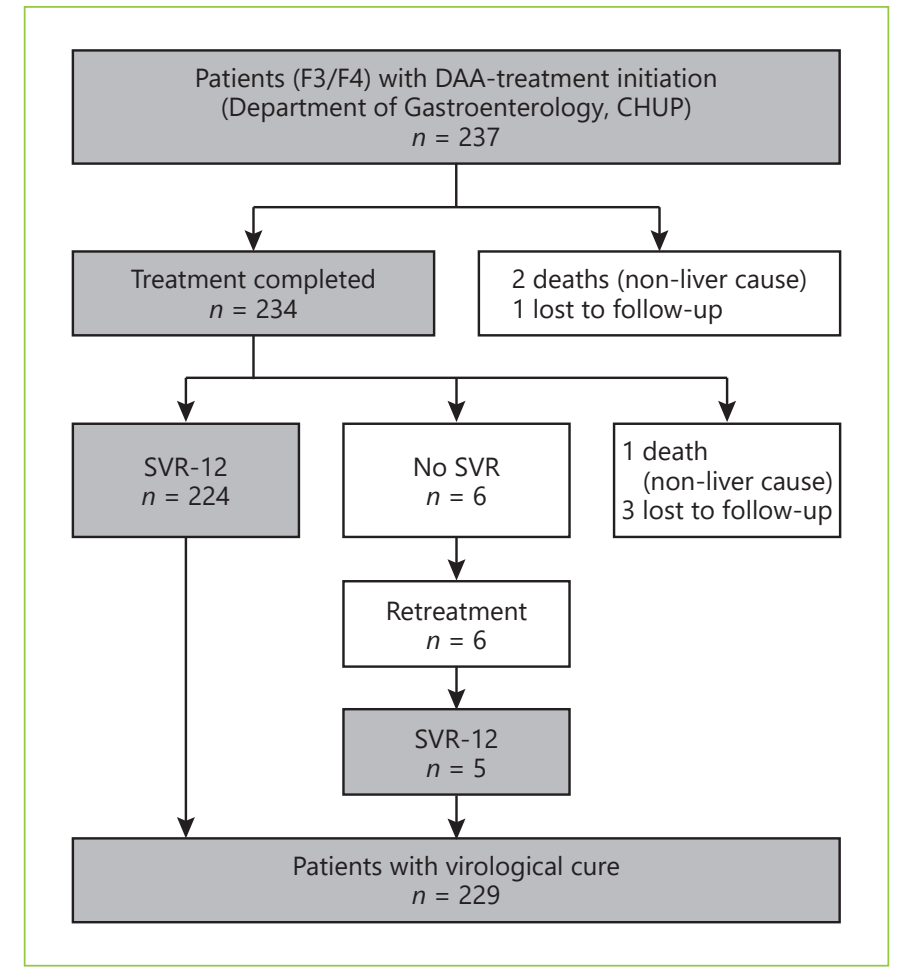

Fig. 1. Study population selection. F3/F4, fibrosis stage F3/F4; DAA, direct-acting antiviral; CHUP, Centro Hospitalar Universitário do Porto; SVR, sustained virological response.

tinuous variables, when applicable, and the $\chi^{2}$ test for dichotomous variables. The Kaplan-Meier method was applied and Cox proportional risk models were constructed to analyze survival and the occurrence of liver decompensation and/or HCC and to identify predictive variables. All tests were two-sided and the results were considered statistically significant at $p<0.05$. Statistical analysis was performed using IBM SPSS Statistics for Windows version 25.0 (IBM, Armonk, NY, USA).

\section{Results}

\section{Characteristics of the Patients}

Of the 237 patients included, 234 completed the treatment, which represents a completion rate of $98.7 \%$ (lost to follow-up: 1; non-liver-related deaths: 2) (Fig. 1). SVR was achieved in 229 patients (per protocol: $97.8 \%$; intention to treat: $96.6 \%)$. Until 12 weeks after EOT, 4 patients were lost (lost to follow-up: 3; non-liver-related death: 1) and 1 patient did not achieve SVR.

The demographic and clinical characteristics of the study population, including patient comorbidities, are shown in Table 1. Approximately 2 and $47 \%$ of the pa- 
Table 1. Demographic and clinical characteristics of the study population at baseline

\begin{tabular}{|c|c|c|c|c|}
\hline Subjects, $n(\%)$ & $229(100)$ & $75(32.8)$ & $154(67.2)$ & $<0.001$ \\
\hline Age, years & $58.12 \pm 11.17$ & $56.39 \pm 10.27$ & $58.98 \pm 11.52$ & 0.144 \\
\hline Male, $n(\%)$ & $157(68.6)$ & $47(62.7)$ & $110(71.4)$ & 0.235 \\
\hline \multicolumn{5}{|l|}{ Comorbidities, $n(\%)$} \\
\hline Diabetes & $44(19.2)$ & $10(13.3)$ & $34(22.1)$ & 0.162 \\
\hline Chronic renal disease & $7(3.1)$ & $2(2.7)$ & $5(3.2)$ & 1.0 \\
\hline Psychiatric disease & $35(15.3)$ & $9(12)$ & $26(16.9)$ & 0.442 \\
\hline Opioid replacement therapy & $9(3.9)$ & $4(5.3)$ & $5(3.2)$ & 0.480 \\
\hline Previous treatment attempts, $n(\%)$ & $113(49.3)$ & $35(46.7)$ & $78(50.6)$ & 0.671 \\
\hline DAA & $5(2.2)$ & $2(2.7)$ & $3(1.9)$ & \\
\hline IFN & $108(47.1)$ & $33(44)$ & $75(48.7)$ & \\
\hline Sexual & $6(2.6)$ & $2(2.7)$ & $4(2.6)$ & \\
\hline Vertical & $1(0.4)$ & - & $1(0.6)$ & \\
\hline Professional & $1(0.4)$ & - & $1(0.6)$ & \\
\hline Unknown & $114(49.8)$ & $31(41.3)$ & $83(53.9)$ & \\
\hline \multicolumn{5}{|l|}{ Genotype, $n(\%)$} \\
\hline Genotype 1 - total & $164(71.6)$ & $50(66.7)$ & $114(74.1)$ & \\
\hline $1 \mathrm{a}$ & $76(33.2)$ & $30(40)$ & $46(29.9)$ & \\
\hline $1 b$ & $78(34.1)$ & $18(24)$ & $60(39)$ & \\
\hline Other subtype & $10(4.4)$ & $2(2.7)$ & $8(5.2)$ & \\
\hline Genotype 2 - total & $2(0.9)$ & - & $2(1.2)$ & - \\
\hline $2 a / b$ & $1(0.4)$ & - & $1(0.6)$ & \\
\hline $2 \mathrm{a} / \mathrm{c}$ & $1(0.4)$ & - & $1(0.6)$ & \\
\hline SOF/DAC & $8(35)$ & $2(2.7)$ & $6(3.9)$ & \\
\hline $\mathrm{SOF}+\mathrm{Rib}$ & $15(6.6)$ & $8(10.7)$ & $7(4.5)$ & \\
\hline $\mathrm{OBV} / \mathrm{PTV} / \mathrm{r}+\mathrm{DSV}$ & $8(3.5)$ & $3(4)$ & $5(3.2)$ & \\
\hline SOF/SIM & $2(0.9)$ & $1(1.3)$ & $1(0.6)$ & \\
\hline $\mathrm{SOF}+$ pegIFN + Rib & $4(1.7)$ & - & $4(2.6)$ & \\
\hline Pretreatment hepatic decompensation, $n(\%)$ & $26(11.4)$ & - & $26(16.9)$ & $<0.001$ \\
\hline Pretreatment HCC, $n(\%)$ & $1(0.4)$ & - & $1(0.65)$ & 0.672 \\
\hline \multicolumn{5}{|l|}{ Extrahepatic manifestations, $n(\%)$} \\
\hline Cryoglobulinemia & $6(2.6)$ & $1(1.3)$ & $5(3.2)$ & 0.667 \\
\hline Lichen planus & $5(2.2)$ & - & $5(3.2)$ & 0.175 \\
\hline Porphyria cutanea tarda & - & - & - & - \\
\hline \multicolumn{5}{|l|}{ Child-Pugh class } \\
\hline A & $147(64.2)$ & - & $147(95.5)$ & - \\
\hline $\mathrm{B} / \mathrm{C}$ & $7(3.1)$ & & $7(4.5)$ & \\
\hline Esophageal varices, $n(\%)$ & $38(16.6)$ & $1(1.3)$ & $37(24)$ & 0.046 \\
\hline Portal hypertension gastropathy, $n$ (\%) & $32(14)$ & $1(1.3)$ & $31(20.1)$ & 0.129 \\
\hline Elastography, $\mathrm{kPa}$ & $20.73 \pm 15.6$ & $10.67 \pm 1.14$ & $26.94 \pm 17.04$ & $<0.001$ \\
\hline Platelets $/ \mathrm{mm}^{3}, n$ & $148,419 \pm 63,195$ & $192,492 \pm 49,080$ & $127,864 \pm 59,902$ & $<0.001$ \\
\hline INR & $1.10 \pm 0.26$ & $1.03 \pm 0.14$ & $1.14 \pm 0.29$ & 0.004 \\
\hline
\end{tabular}


Table 1 (continued)

\begin{tabular}{|c|c|c|c|c|}
\hline Total bilirubin, $\mathrm{mg} / \mathrm{dL}$ & $0.76 \pm 0.46$ & $0.62 \pm 0.32$ & $0.85 \pm 0.51$ & $<0.001$ \\
\hline Albumin, mg/dL & $4.34 \pm 0.49$ & $4.46 \pm 0.41$ & $4.26 \pm 0.52$ & $<0.001$ \\
\hline AST, U/L & $73.93 \pm 46.48$ & $70.66 \pm 53.95$ & $77.92 \pm 44.93$ & 0.325 \\
\hline ALT, U/L & $92.13 \pm 80.36$ & $103 \pm 116.16$ & $88.8 \pm 63.42$ & 0.166 \\
\hline ALP, U/L & $88.86 \pm 36.99$ & $75.59 \pm 26.06$ & $95.73 \pm 39.53$ & $<0.001$ \\
\hline Creatinine, $\mathrm{mg} / \mathrm{dL}$ & $0.82 \pm 0.25$ & $0.8192 \pm 0.23$ & $0.8207 \pm 0.27$ & 0.964 \\
\hline
\end{tabular}

Values denote the mean \pm SD unless specified otherwise. DAA, direct-acting antivirals; IFN, interferon; EOT, end of treatment; HCV, hepatitis C virus; SOF, sofosbuvir; LED, ledipasvir; DAC, daclatasvir; Rib, ribavirin; OBV/PTV/r, ombitasvir/paritaprevir/ritonavir; DSV, dasabuvir; SIM, simeprevir; HCC, hepatocellular carcinoma.

tients had previously been treated with DAA and IFNbased regimens, respectively. Of the patients with SVR, $68.6 \%$ were male $(n=157)$ with a mean age of 58 years (SD 11.17). The main risk factor for HCV transmission identified was intravenous drug use in $31 \%(n=70)$. Genotype 1 was the most prevalent (71.6\%), followed by genotype $3(18.3 \%)$. The majority was diagnosed with cirrhosis based on the elastography value $(72.5 \%)$, a liver biopsy (6.1\%), clinical grounds (10\%), or a combination of the last (11.4\%). At baseline, 154 patients (67.2\%) had cirrhosis, most of them CP class A (CP-A; $n=147$; 95.5\%). Esophagogastroduodenoscopy data were available on 162 patients at baseline ( 38 with EV) and on an additional 99 patients after EOT (21 patients with EV). Of the patients with EV at baseline, 31 had small and 7 large varices. Eleven patients were in primary eradication programs, 2 in secondary eradication, and 2 had eradicated EV.

\section{Follow-Up and Survival}

The duration of treatment varied between 8 and 24 weeks, and the maximum follow-up time after EOT was 30 months (2.5 years). The SVR population had a medium follow-up time of 27.73 months (SD 1.85). During follow-up, the overall and the liver-related mortality was $4.4 \%$ (19/1,000 person-years) and 2.2\% (9.5/1,000 person-years), respectively.

On average, the deaths occurred 14.5 months after EOT (SD 10.5). Five patients (2.2\%) died of liver-related causes $(1[0.4 \%]$ of liver decompensation and 4 [1.7\%] of HCC) and 5 patients (2.2\%) of non-liver-related causes (1 of hemorrhagic stroke, 2 of lung carcinoma, 1 of mesenteric ischemia after nephrectomy, and 1 of cranioencephalic trauma). All deaths occurred among patients with $\mathrm{CP}-\mathrm{A}$ at baseline. The mortality rate was significantly higher among cirrhotic patients $(p=0.025$; Fig. 2$)$ and

Real-World Follow-Up after

DAA-Induced SVR tended to be higher among patients with an initial MELD score $>10$ ( 6.9 vs. $4.4 \% ; p=0.63$ ). In multivariate analysis, a history of pretreatment decompensation was significantly associated with a 5-times-higher risk of mortality (HR 4.92; 95\% CI: $1.22-19.69 ; p=0.024$ ).

With regard to the laboratory parameters, there was an improvement in platelet, transaminase, and albumin serum values in the F3 and cirrhotic patients 1 year after EOT (online suppl. Table S1; for all online suppl. material, see www.karger.com/doi/10.1159/000503074). A significant improvement in platelet serum values was maintained between 1 year and 2 years after EOT (F3: $p=0.041$; F4: $p<0.001$ ). Between EOT and 12 weeks after EOT, there was a statistically significant decrease in transaminase values in the cirrhotic patients - however, at a magnitude lower than the initial decrease between baseline and EOT.

Of the initial $147 \mathrm{CP}$-A patients, 8 (5.4\%) evolved to $\mathrm{CP}-\mathrm{B}$ during follow-up, 5 of whom had a history of pretreatment decompensation. Of the initial $7 \mathrm{CP}-\mathrm{B}$ patients, $4(57.1 \%)$ regressed to $\mathrm{CP}-\mathrm{A}$ during follow-up and 2 $(28.6 \%)$ remained at CP-B, with no data on the post-EOT CP score for 1 patient.

Among the 85 patients undergoing endoscopy both at baseline and after EOT, we found de novo EV occurrence, an increased size, and/or variceal upper gastrointestinal bleeding in $10.6 \%$ during follow-up. The baseline and post-EOT endoscopic findings are described in Figure 3.

At 12 weeks after EOT, there was a mean reduction of $5.6 \mathrm{kPa}$ in elastography values compared to baseline ( 20.47 vs. $14.86 \mathrm{kPa} ; p<0.001 ; n=78$ ), significantly different than the values from 1 year after EOT ( 17.55 vs. 13 $\mathrm{kPa} ; p=0.001 ; n=48)$. Two years after EOT, the elastography values showed a mean reduction of $6.23 \mathrm{kPa}$ compared to baseline (18.64 vs. $12.4 \mathrm{kPa} ; p<0.001 ; n=37$ ). 
Fig. 2. Survival curve after end of treatment.

Fig. 3. Evolution of baseline and post-EOT endoscopic findings. EOT, end of treatment; EV, esophageal varices.
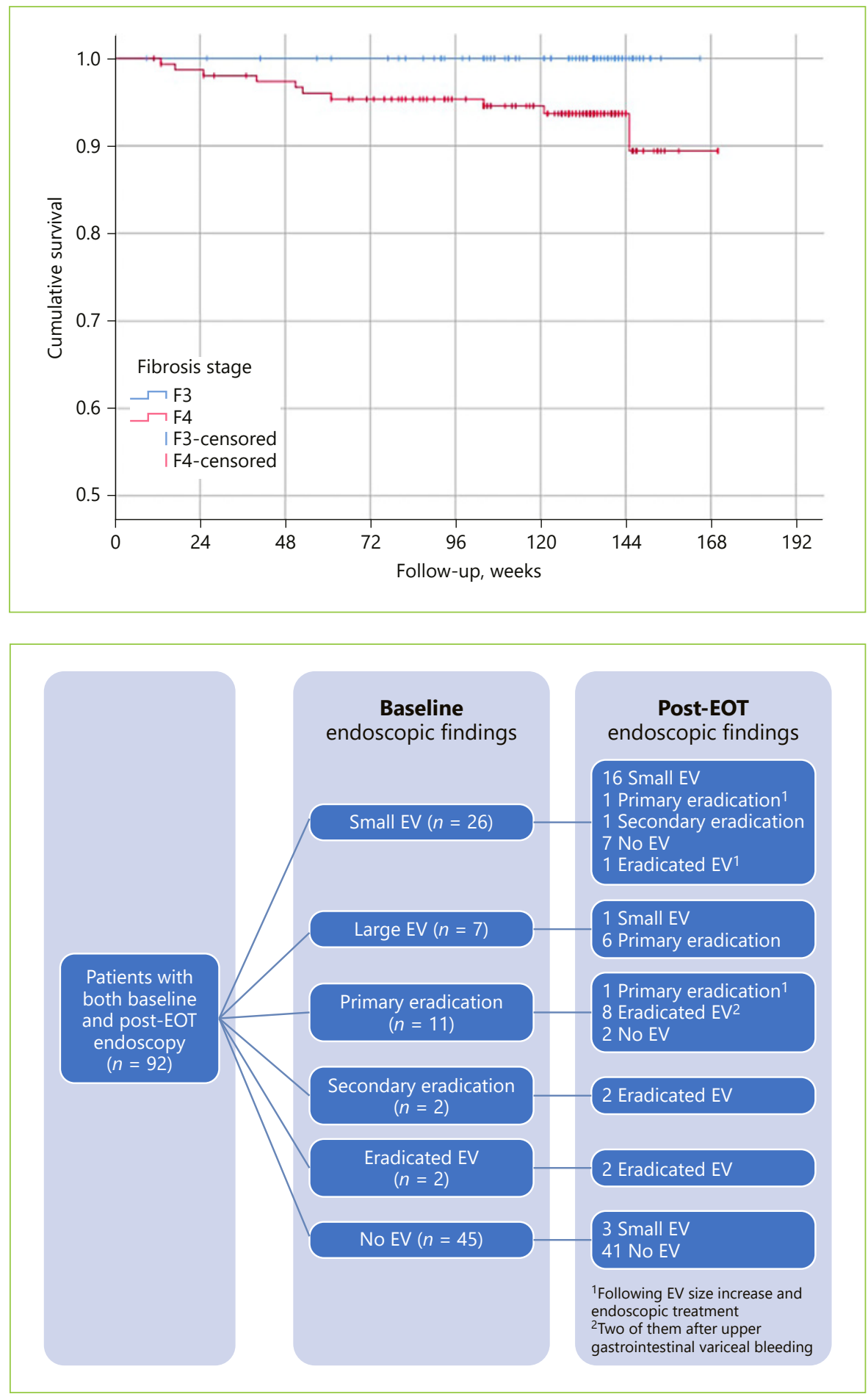

Regarding the cirrhotic patients, those who had an early regression (reduction of $\geq 30 \%$ from baseline) of liver stiffness at 24 weeks after EOT had, on average, higher baseline elastography values ( $28.52 \pm 16.8$ vs. $19.15 \pm 5.1$; $p=0.03 ; n=31$ ).

\section{Liver Decompensation Events}

During Treatment

Liver decompensation occurred in 5 patients $(3.24 \%$ of the cirrhotic patients) during the treatment period (online suppl. Table S2). All patients were CP-A, with a high- 
Table 2. HCC during follow-up

\begin{tabular}{lll}
\hline & During treatment & After EOT \\
\hline Mean diagnosis time after treatment/EOT \pm SD, weeks & $18.75 \pm 3.86$ & $80 \pm 6.2$ \\
BCLC stage at diagnosis & 4 & 1 \\
A & - & 5 \\
B & - & 2 \\
Baseline fibrosis stage & 4 & 4 \\
F3 & 1 (after TACE) & - \\
F4 & 2 & 1 \\
HCC treatment & 1 & 4 \\
Liver transplantation & 3 deaths & 2 deaths (1 after head trauma) \\
RFTA & $(1$ after HCC recurrence in liver graft) & 1 post-TACE recurrence \\
TACE & 1 remission & 2 progression \\
Outcome at the end of follow-up & & 1 remission \\
\end{tabular}

HCC, hepatocellular carcinoma; EOT, end of treatment; BCLC, Barcelona Clinic Liver Cancer; RFTA, radiofrequency thermoablation; TACE, transarterial chemoembolization.

er baseline MELD score (10 vs. 8.03; $p=0.048$ ) and a higher baseline age (67 vs. 57.9 years; $p=0.073$ ).

\section{After EOT}

Liver decompensation events occurred in 13 patients ( $8.4 \%$ of the cirrhotic patients), on average 15.3 months (SD 6.2) after EOT. The incidence rate was $25 / 1,000$ person-years. Ten patients had a history of pretreatment hepatic decompensation and 2 patients had it during treatment. Liver decompensation events were more frequent among baseline CP-B patients than among baseline CP-A patients $(n=4[57.1 \%]$ vs. $n=9[6.1 \%] ; p<0.001)$, as well as among patients with an initial MELD score $>10(n=5$ [17.2\%] vs. $n=7$ [3.9\%]; $p=0.014)$.

Ascites was the most common liver decompensation event and occurred in 11 patients (7.1\% of the cirrhotics), of whom 4 were CP-B. Subsequent events of decompensation, other than ascites, were found in 4 of these patients. Inaugural upper gastrointestinal variceal bleeding occurred in 3 patients (1 CP-B). Three patients (1.95\% of the cirrhotics) had episodes of hepatic encephalopathy. The clinical outcomes of the liver decompensation events are described in online supplementary Table S2.

\section{Hepatocellular Carcinoma}

De novo HCC was diagnosed in 10 patients: in 4 patients during treatment and in 6 patients 1 year after EOT. Concerning the stage of liver disease at baseline, 2 pa- tients had stage $\mathrm{F} 3$ fibrosis and 8 patients were cirrhotic at CP-A (5.2\% of the cirrhotic patients). The 4 patients diagnosed during treatment were $\mathrm{CP}-\mathrm{A}$.

The post-EOT incidence of HCC was $2.7 \%(n=6 / 225)$, with an incidence rate of 11.6/1,000 person-years. During treatment, HCC was diagnosed, on average, 19 weeks ( \pm 3.86 ; range: $15-24)$ after therapy initiation. HCC was diagnosed, on average, 18.4 months $( \pm 6.2)$ after EOT.

Forty percent of the patients were infected with $\mathrm{HCV}$ genotype $3,40 \%$ with genotype $1 \mathrm{~b}$, and $20 \%$ with genotype $1 \mathrm{a}$. The HCC rate tended to be higher among patients with MELD scores $>10$ at baseline (10.3 vs. 3.9\%; $p=0.297)$.

Of the overall patients with an HCC diagnosis, 5 patients presented with Barcelona Clinic Liver Cancer (BCLC) stage A and 5 patients with BCLC-B. Five patients underwent transarterial chemoembolization (TACE), 3 patients underwent radiofrequency thermoablation, 1 patient received a liver transplant (after TACE treatment), and 1 patient died before the start of HCC treatment. Among the patients submitted to TACE, 1 patient had HCC recurrence and the disease progressed in 4 patients, of whom 2 died ( 5 and 6 months after TACE). The patient with a transplant died 1 year and 4 months after transplantation due to recurrence of the disease in the liver graft. Of the patients undergoing radiofrequency thermoablation, 2 were cured from malignancy at the end of follow-up and 1 died from disease progression. Table 


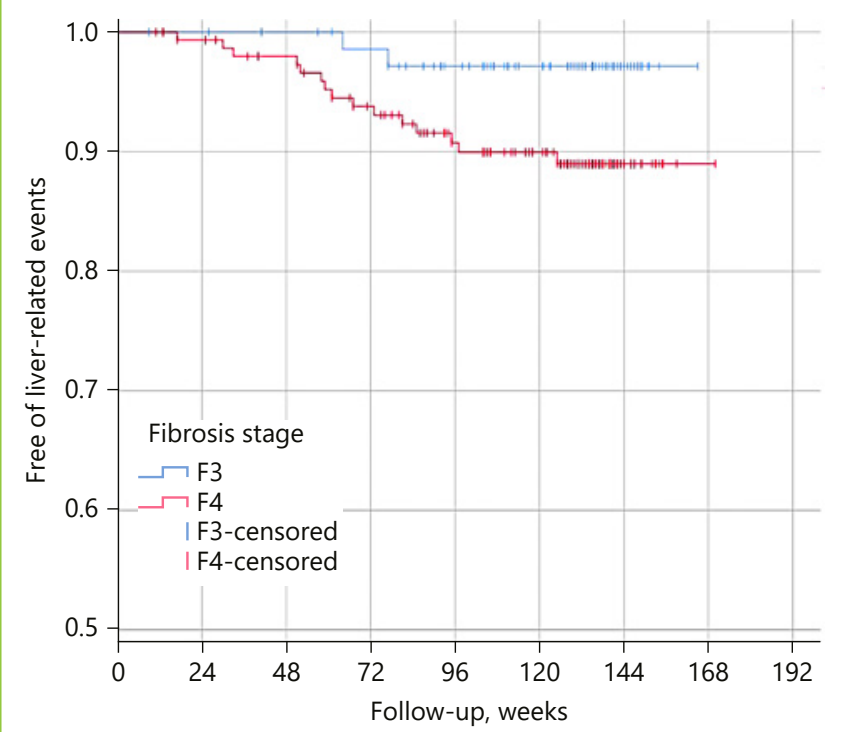

Fig. 4. Liver-related adverse events after end of treatment.

2 shows the differences between the HCC diagnoses during treatment and after EOT.

The mortality rate following an HCC diagnosis was $50 \%$ ( 4 died of HCC progression and 1 died of head trau$\mathrm{ma}$ ) and $30 \%$ had disease progression by the end of follow-up. The mean survival after diagnosis was 15.25 months. The HCC mortality rate in the study population was $1.7 \%(n=4 / 229)$.

In multivariate analysis, the occurrence of adverse liver events (defined as the occurrence of liver decompensation and/or HCC diagnosis after EOT) (Fig. 4) was significantly associated with a history of pretreatment decompensation (HR 19.474; 95\% CI: 4.156-91.239; $p<$ 0.001 ) and a lower baseline serum platelet count (HR $0.979 ; 95 \%$ CI $0.960-0.998 ; p=0.031$ ) and lower albumin values (HR 0.181; 95\% CI: 0.044-0.740; $p=0.017 ; p<$ 0.001 ). Considering solely the occurrence of HCC, only a history of pretreatment decompensation was significantly associated with this outcome (HR 9.053; 95\% CI: 1.44656.692; $p=0.019$ ).

\section{Liver Transplantation}

Only 1 of the 154 cirrhotic patients (0.64\%) received a transplant, 17.3 months after EOT, due to HCC. HCC recurred in the liver graft, and the patient died 1 year and 4 months after transplantation.
Of the 2 patients listed for liver transplantation at baseline, 1 was delisted due to improvement in clinical parameters and 1 was kept on the list. One patient was listed for liver transplantation after EOT, following a 6-point increase in his MELD score and progression from CP-A to CP-C during follow-up.

\section{Discussion and Conclusion}

To the best of our knowledge, this work represents the first single-center national study on the long-term followup of a real-life cohort of patients with advanced liver disease after DAA-induced SVR. Since the introduction of DAA in Portuguese clinics, the evaluation of posttreatment medium- to long-term outcomes has been limited. The follow-up periods presented in this study are the ones possible to date. Our data demonstrate that SVR is durable, which is corroborated by other multicenter observational studies [17].

The patients included did not present significant differences regarding the demographic characteristics and comorbidity prevalence when compared with other cohorts [4, 18-20]. The most prevalent HCV genotype was genotype 1 , followed by genotype 3 , matching recent epidemiological studies on the geographical distribution of HCV in Portugal $[21,22]$. On the other hand, we had a lower proportion of $\mathrm{CP}-\mathrm{B} / \mathrm{C}$ patients at baseline. Limitations in the use of the first DAA in certain comorbid states [23], and underrepresentation due to allocation to liver pretransplant consultation, might have limited the number of $\mathrm{CP}-\mathrm{B} / \mathrm{C}$ patients present at baseline, a fact that should be considered in data interpretation.

With the emergence of pangenotypic DAA with shorter treatment regimens, higher completion rates are expected [19]. Applying these characteristics to the intention-to-treat population ( $n=237), 79.3 \%$ could have undergone shorter treatments. Still, our cohort presents an excellent treatment completion rate (98.7\%), like those of other European cohorts $[4,18]$.

The low overall and liver-related mortality rates in our cohort support the favorable prognosis of patients with advanced liver disease after DAA-induced SVR, reinforcing this target as an independent survival factor in these patients $[6,20,24,25]$. Epidemiological data from the USA on the causes of liver-related death showed a decrease in mortality from HCV infection with the introduction of DAA treatments [26]. In our cohort, deaths occurred only among the CP-A patients, contradicting not only the literature $[4,18,19,27]$ but also the natural 
history of the disease [28]. Our findings may be explained by the low number of CP-B and -C patients at baseline. Half of the overall mortality in our cohort was liver related, and amongst these cases, $80 \%$ was due to HCC. The presence of liver cirrhosis was associated with higher overall mortality rates.

The incidence rate of liver decompensations after EOT was $25 / 1,000$ person-years, a similar outcome to the rates shown in studies with SVR with IFN or DAA treatments $[20,24]$. When compared with a historical cohort of patients treated with IFN and without SVR, our cohort presented a lower incidence of HCC (11.6 vs. 18.8/1,000 person-years) and liver-related death (9.5 vs. 14.4/1,000 person-years). Regarding liver-related complications, our cohort showed a higher incidence than the IFN cohort (25 vs. 18.8/1,000 person-year) [29].

Considering CP-A patients, 5.4\% progressed to CP-B after EOT, and we could identify, in $50 \%$ of these patients, the concomitant presence of other liver injury factors such as a high BMI and continued alcohol abuse after SVR [30]. In addition to cofactors of liver injury, $62.5 \%$ of the patients had a pretreatment history of decompensation, a parameter that, in multivariate analysis, remained significantly associated with the occurrence of liver-related adverse events and mortality after EOT. This association was not verified for age, a high BMI, dyslipidemia, and diabetes. Patients' pretreatment disease history may thus be a more important long-term prognostic factor than the CP class at treatment initiation, a conclusion that is in line with the results presented in a European multicenter study [4]. Regarding our CP-B or -C patients, $57.1 \%$ sustainedly evolved to CP-A at the end of the follow-up period. Recent studies have reported sustained conversion rates to $\mathrm{CP}-\mathrm{A}$ above $50 \%$ among decompensated patients after DAA-induced SVR $[4,19,31]$.

Despite the lack of systematic data regarding postEOT transient elastography in our cohort, our results corroborate the increasing evidence of liver stiffness improvement in F3 or cirrhotic patients after SVR [17]. This may result from a decrease in necroinflammatory activity after SVR which may lead to overestimation of fibrosis regression [32-34], a fact that has also been demonstrated by matched elastography-biopsy comparison [35]. Regarding F4 patients, those with an "early regression" (decrease in hepatic stiffness $\geq 30 \% 24$ weeks after EOT) [36] had higher baseline elastography values, which supports the role of inflammatory activity reduction in this context.

Although direct measurement of the effect of SVR on portal hypertension was not done in our cohort, an indi- rect evaluation showed a bleeding rate of $3.2 \%$ among patients with small $\mathrm{EV}$ at baseline, a rate known to be lower than that among cirrhotic patients with small varices in general (bleeding rate 5-15\%) [37]. The statistically significant and sustained increase in serum platelet counts in our cohort suggests that there is a progressive improvement in the degree of portal hypertension and, probably, in the degree of liver fibrosis after EOT, which has also been documented in the literature $[34,38]$.

The number of patients on the liver transplant waiting list remained unchanged between baseline and the end of follow-up (one patient was delisted and another was listed after EOT). Treatment of waitlisted patients with decompensated cirrhosis may create a paradoxical decrease in MELD scores after EOT with loss of eligibility or priority for liver transplantation, without translating into a significant improvement in quality of life or long-term clinical outcomes $[6,39]$. The challenge remains in determining which patients have no benefit from pretransplant therapy and in whom significant improvement after viral eradication is unlikely.

In our cohort, the diagnosis of HCC during treatment on average occurred 19 weeks after treatment initiation. Early detection of HCC in these patients suggests the likely presence of undetectable dysplastic nodules prior to treatment initiation [19]. The occurrence of HCC during treatment with DAA does not appear to be associated with greater tumor aggressiveness, and, in this study, all the patients diagnosed during treatment were BCLC-A [40]. After EOT, 6 patients developed HCC, which represents an incidence rate of $11.6 / 1,000$ person-years (a total incidence of $2.7 \%$ ), similar to the results reported in other real-world studies [40-44]. Contrary to the initial reports about effects of DAA on the HCC incidence, recent data from larger cohorts, adjusted for confounding factors, linked DAA-induced HCV cure with a lower risk of HCC. This reduction was similar to the post-SVR risk reduction seen with IFN treatments $[17,39,44]$.

The number of patients with an HCC diagnosis in our study was too low to establish comparisons between those diagnosed during and those diagnosed after treatment completion. All the 4 patients diagnosed with HCC during treatment presented with BCLC stage A tumor, as opposed to 1 patient (out of 6 ) diagnosed after EOT. This may be explained by the earlier tumor detection in the first group, where 2 of the patients had less than a 6-month interval between the baseline US and the diagnosis of HCC. On the other hand, the higher mortality in this group of patients may be associated with a longer followup period. 
The effect of DAA-induced SVR on HCC recurrence is still controversial. In our study, no recurrence occurred.

In our cohort, 9 patients were discharged to primary health care units, 7 of whom had an F0-F1 stage in more than one elastography after EOT. After virological cure, there is still a residual risk of HCC occurrence in these patients [11]. It is not yet clear whether the risk of HCC continues to decline over time, or if laboratory/elastography parameters can predict the risk of HCC development. There is reason to believe that progressive reduction of fibrosis after EOT may translate into a long-term continued HCC risk reduction. However, patient aging may modify this assumption [24], making it imperative to identify clinical characteristics and predictive biomarkers able to define groups which could benefit from post-SVR HCC screening [39].

Our work demonstrates results for a large real-world and single-center cohort with a longer duration of followup, considering other studies on the long-term clinical outcomes of DAA treatment. It is noteworthy that longer follow-up periods were achieved for patients with more advanced liver disease, since they were prioritized for treatment at the beginning. One of the limitations is that there was no control group with non-SVR patients for outcome comparison. The small number of cirrhotic CP$\mathrm{B} /-\mathrm{C}$ patients limits the assessment of this subset of patients, increasingly treated with success. The heterogeneity of the available data regarding the use of some complementary examinations by different physicians also limited the conclusions derived from their interpretation.

In conclusion, our data confirm that the post-DAA SVR is durable. We found an excellent treatment comple- tion rate, with SVR associated with improvement in liver parameters. We also obtained indirect signs suggestive of a progressive decrease in the portal hypertension gradient and liver fibrosis. Patients with advanced liver disease presented a favorable prognosis, with a low incidence rate of liver decompensations among the F4 patients. The risk of liver decompensation after EOT was significantly associated with a pretreatment history of decompensation, a low liver synthesis capacity, and clinically significant portal hypertension at baseline. Cure of the infection reduces - but does not eliminate the risk of - HCC or liver disease progression, especially in the presence of other causes of liver dysfunction.

\section{Statement of Ethics}

The study protocol, data collection, and analysis were approved by the local Ethics Committee (N/RFE ${ }^{\mathrm{a}}$ 2018.262(226-DEFI/226CES)). The authors have no ethical conflicts to disclose.

\section{Disclosure Statement}

The authors have no conflicts of interest to declare.

\section{Author Contributions}

T.P.G. and I.P. conceived and designed the analysis; T.P.G., P.F., M.G., J.S., and D.F. collected the data; P.F. and C.L. performed the data analysis; T.P.G., P.F., and C.L. contributed to data interpretation; T.P.G. and P.F. wrote the paper; all authors reviewed the final manuscript.

\section{References}

1 Blach S, Zeuzem S, Manns M, Altraif I, Duberg AS, Muljono DH, et al.; Polaris Observatory HCV Collaborators. Global prevalence and genotype distribution of hepatitis $\mathrm{C}$ virus infection in 2015: a modelling study. Lancet Gastroenterol Hepatol. 2017 Mar;2(3):16176.

2 Velosa J. Why is viral eradication so important in patients with HCV-related cirrhosis? Antivir Ther. 2017;22(1):1-12.

3 Norma de Orientação Clínica - Tratamento da Hepatite C crónica no adulto [Internet]. Available from: https://www.dgs.pt/directrizes-da-dgs/normas-e-circulares-normativas/ norma-n-0282017-de-28122017.aspx2017.
4 Kozbial K, Moser S, Al-Zoairy R, Schwarzer R, Datz C, Stauber R, et al. Follow-up of sustained virological responders with hepatitis $\mathrm{C}$ and advanced liver disease after interferon/ ribavirin-free treatment. Liver Int. 2018 Jun; 38(6):1028-35.

5 Roche B, Coilly A, Duclos-Vallee JC, Samuel $D$. The impact of treatment of hepatitis $C$ with DAAs on the occurrence of HCC. Liver Int. 2018 Feb;38 Suppl 1:139-45.

6 van der Meer AJ, Berenguer M. Reversion of disease manifestations after $\mathrm{HCV}$ eradication. J Hepatol. 2016 Oct;65(1 Suppl):S95-108.
7 INFARMED. Hepatite C - Monitorização dos tratamentos [Internet]. 2019 [updated 2019 May 22]. Available from: https://www.sns. gov.pt/noticias/2017/07/25/sns-tratamentoshepatite-c/. INFARMED - Autoridade Nacional do Medicamento e Produtos de Saúde, I.P.; 2019.

8 European Association for the Study of the Liver. EASL Recommendations on Treatment of Hepatitis C 2018. J Hepatol. 2018 Aug; 69(2):461-511.

9 Innes HA, McDonald SA, Dillon JF, Allen S, Hayes PC, Goldberg D, et al. Toward a more complete understanding of the association between a hepatitis $C$ sustained viral response and cause-specific outcomes. Hepatology. 2015 Aug;62(2):355-64. 
10 Hsu CS, Huang CJ, Kao JH, Lin HH, Chao YC, Fan YC, et al. Interferon-based therapy decreases risks of hepatocellular carcinoma and complications of cirrhosis in chronic hepatitis C patients. PLoS One. 2013 Jul; 8(7):e70458.

11 Galle PR, Forner A, Llovet JM, Mazzaferro V, Piscaglia F, Raoul JL, et al.; European Association for the Study of the Liver. Management of hepatocellular carcinoma. J Hepatol. 2018 Jul;69(1):182-236.

12 Mallet V, Gilgenkrantz H, Serpaggi J, Verkarre $\mathrm{V}$, Vallet-Pichard A, Fontaine $\mathrm{H}$, et al. Brief communication: the relationship of regression of cirrhosis to outcome in chronic hepatitis C. Ann Intern Med. 2008 Sep;149(6): 399-403.

13 D’Ambrosio R, Aghemo A, Rumi MG, Ronchi G, Donato MF, Paradis V, et al. A morphometric and immunohistochemical study to assess the benefit of a sustained virological response in hepatitis $\mathrm{C}$ virus patients with cirrhosis. Hepatology. 2012 Aug;56(2):532-43.

14 Poynard T, McHutchison J, Manns M, Trepo C, Lindsay K, Goodman Z, et al. Impact of pegylated interferon alfa- $2 \mathrm{~b}$ and ribavirin on liver fibrosis in patients with chronic hepatitis $\mathrm{C}$. Gastroenterology. 2002 May;122(5):1303-13.

15 Rodrigues J, Tato-Marmho R, Mota-Filipe H, Martins AP, Martins JC, Andreozzi V, et al. Evidence of Impressive Real World SVR from the Portuguese Ledipasvir/Sofosbuvir and Sofosbuvir Universal Coverage Program to Eradicate (Eliminate) Hepatitis C. J Hepatol. 2016;64(2 Suppl):S224.

16 de Franchis R; Baveno VI Faculty. Expanding consensus in portal hypertension: report of the Baveno VI Consensus Workshop: stratifying risk and individualizing care for portal hypertension. J Hepatol. 2015 Sep;63(3):743-52.

17 Wei L, Huang YH. Long-term outcomes in patients with chronic hepatitis $\mathrm{C}$ in the current era of direct-acting antiviral agents. Expert Rev Anti Infect Ther. 2019 May; 17(5): 311-25.

18 Calvaruso V, Petta S, Cacciola I, Cabibbo G, Cartabellotta F, Di Rosolini A, et al. Disease outcomes after DAA-induced SVR: data from the RESIST-HCV cohort. The International Liver Congress, Paris, 11-15 April 2018.

19 Muir AJ, Mangia A, Lawitz E, Gane E, Conway B, Ruane PJ, et al. 290 - Long-Term Follow-Up of Patients with Chronic HCV Infection and Compensated or Decompensated Cirrhosis following Treatment with Sofosbuvir-Based Regimens. Gastroenterology. 2018; 154(6):S-1081.

20 Nahon P, Bourcier V, Layese R, Audureau E, Cagnot C, Marcellin P, et al. Eradication of Hepatitis C Virus Infection in Patients with Cirrhosis Reduces Risk of Liver and Non-Liver Complications. Gastroenterology. 2017 Jan;152(1):142-56.e2.

21 Pádua E, Avó AP, Almeida C, Água Doce I, Cortes Martins H. Assessment of Hepatitis C Virus Diversity in Addition to the Frequency of Genotypes in Samples Analyzed between
2009 and 2014 at the Reference Laboratory of National Health Institute Dr. Ricardo Jorge [in Portuguese]. Acta Med Port. 2015 NovDec;28(6):695-701.

22 Palladino C, Ezeonwumelu IJ, Marcelino R, Briz V, Moranguinho I, Serejo F, et al. Epidemic history of hepatitis $C$ virus genotypes and subtypes in Portugal. Sci Rep. 2018 Aug; $8(1): 12266$.

23 Zoulim F, Liang TJ, Gerbes AL, Aghemo A, Deuffic-Burban S, Dusheiko G, et al. Hepatitis $C$ virus treatment in the real world: optimising treatment and access to therapies. Gut. 2015 Nov;64(11):1824-33.

24 van der Meer AJ, Feld JJ, Hofer H, Almasio PL, Calvaruso V, Fernández-Rodríguez CM, et al. Risk of cirrhosis-related complications in patients with advanced fibrosis following hepatitis C virus eradication. J Hepatol. 2017 Mar;66(3):485-93.

25 Rutter K, Stättermayer AF, Beinhardt S, Scherzer TM, Steindl-Munda P, Trauner M, et al. Successful anti-viral treatment improves survival of patients with advanced liver disease due to chronic hepatitis C. Aliment Pharmacol Ther. 2015 Mar;41(6):521-31.

26 Kim D, Li AA, Gadiparthi C, Khan MA, Cholankeril G, Glenn JS, et al. Changing Trends in Etiology-Based Annual Mortality from Chronic Liver Disease, from 2007 through 2016. Gastroenterology. 2018 Oct;155(4): 1154-63.e3.

27 Backus LI, Belperio PS, Shahoumian TA, Mole LA. Impact of Sustained Virologic Response with Direct-Acting Antiviral Treatment on Mortality in Patients with Advanced Liver Disease. Hepatology. 2019 Feb;69(2): 487-97.

28 Durand F, Valla D. Assessment of the prognosis of cirrhosis: Child-Pugh versus MELD. J Hepatol. 2005;42 Suppl(1):S100-7.

29 Bruno S, Stroffolini T, Colombo M, Bollani S, Benvegnù L, Mazzella G, et al.; Italian Association of the Study of the Liver Disease (AISF). Sustained virological response to interferon- $\alpha$ is associated with improved outcome in HCV-related cirrhosis: a retrospective study. Hepatology. 2007 Mar;45(3):57987.

30 Wieland A, Everson GT. Co-Existing Hepatitis $\mathrm{C}$ and Alcoholic Liver Disease: A Diminishing Indication for Liver Transplantation? Alcohol Alcohol. 2018 Mar;53(2):187-92.

31 Gentile I, Scotto R, Coppola C, Staiano L, Amoruso DC, De Simone T, et al. Treatment with direct-acting antivirals improves the clinical outcome in patients with HCV-related decompensated cirrhosis: results from an Italian real-life cohort (Liver Network Activity-LINA cohort). Hepatol Int. 2019 Jan; 13(1):66-74.

32 Bruno G, Saracino A, Fabrizio C, Scudeller L, Milella M, Angarano G. Rapid improvement in liver fibrosis in HCV-infected patients with or without HIV infection and DAA-induced SVR: a "turning-off" effect of liver inflammation? J Viral Hepat. 2017 Feb;24(2):174-5.
33 Knop V, Hoppe D, Welzel T, Vermehren J, Herrmann E, Vermehren A, et al. Regression of fibrosis and portal hypertension in HCVassociated cirrhosis and sustained virologic response after interferon-free antiviral therapy. J Viral Hepat. 2016 Dec;23(12):994-1002.

34 Chekuri S, Nickerson J, Bichoupan K, Sefcik R, Doobay K, Chang S, et al. Liver Stiffness Decreases Rapidly in Response to Successful Hepatitis C Treatment and Then Plateaus. PLoS One. 2016 Jul;11(7):e0159413.

35 Pockros P, Crissien-Martinez AM, Frenette C, Skillin C, Bao F, Du E, et al. Degree of liver fibrosis regression predicted by transient elastography after cure of chronic hepatitis $\mathrm{C}$ with direct acting antivirals is overestimated but confirmed by liver biopsy. J Hepatol. 2017; 66(1):S108

36 ANRS CO13 HEPAVIH Cohort. Regression of liver stiffness after sustained hepatitis $\mathrm{C}$ virus (HCV) virological responses among HIV/ HCV-coinfected patients. AIDS. 2015 Sep; 29(14):1821-30.

37 LaBrecque D, Khan A, Sarin S, Le Mair A. Esophageal varices. World Gastroenterology Organisation Global Guidelines. Milwaukee, WI: World Gastroenterology Organisation; 2014. pp. 1-14.

38 Miyaki E, Imamura M, Hiraga N, Murakami E, Kawaoka T, Tsuge M, et al. Daclatasvir and asunaprevir treatment improves liver function parameters and reduces liver fibrosis markers in chronic hepatitis C patients. Hepatol Res. 2016 Jul;46(8):758-64.

39 Ioannou GN, Feld JJ. What Are the Benefits of a Sustained Virologic Response to DirectActing Antiviral Therapy for Hepatitis C Virus Infection? Gastroenterology. 2019 Jan; 156(2):446-460.e2.

40 Kanwal F, Kramer J, Asch SM, Chayanupatkul M, Cao Y, El-Serag HB. Risk of Hepatocellular Cancer in HCV Patients Treated with Direct-Acting Antiviral Agents. Gastroenterology. 2017 Oct;153(4):996-1005.e1.

41 Conti F, Buonfiglioli F, Scuteri A, Crespi C, Bolondi L, Caraceni P, et al. Early occurrence and recurrence of hepatocellular carcinoma in HCV-related cirrhosis treated with directacting antivirals. J Hepatol. 2016 Oct;65(4): 727-33.

42 Mettke F, Schlevogt B, Deterding K, Wranke A, Smith A, Port K, et al. Interferon-free therapy of chronic hepatitis $\mathrm{C}$ with direct-acting antivirals does not change the short-term risk for de novo hepatocellular carcinoma in patients with liver cirrhosis. Aliment Pharmacol Ther. 2018 Feb;47(4):516-25.

43 Calvaruso V, Cabibbo G, Cacciola I, Petta S, Madonia S, Bellia A, et al. Incidence of Hepatocellular Carcinoma in Patients with HCVAssociated Cirrhosis Treated with DirectActing Antiviral Agents. Gastroenterology. 2018 Aug;155(2):411-21.e4.

44 Ioannou GN, Green PK, Berry K. HCV eradication induced by direct-acting antiviral agents reduces the risk of hepatocellular carcinoma. J Hepatol. 2017 [Epub ahead of print]. 